\title{
CONSIDERACIONES SOBRE EL CONCEPTO DE LEY NATURAL EN SAN PABLO
}

\author{
Carlos lópez Bravo \\ Profesor Titular de Filosofía del Derecho. Universidad de Sevilla
}

\begin{abstract}
RESUMEN
El concepto de ley natural reflejado en los dos primeros capítulos de la Carta de San Pablo a los Romanos, significa, en la historia de la Filosofía jurídica, el nacimiento de un nuevo Iusnaturalismo, que con raíces en el pensamiento clásico grecorromano, se fundamenta en la nueva dimensión antropológica que proporciona el Cristianismo. A partir del posicionamiento crítico del Apóstol ante la ley mosaica, se analiza esa idea de una ley no escrita que fluye de la naturaleza humana, está presente en los corazones de todos los hombres, y actúa al servicio de la gracia y la verdadera justicia, representada por el Evangelio. Una ley natural que constituye además prueba inequívoca de la existencia de una ética y de una teología naturales basadas en la razón.
\end{abstract}

Palabras claves: San Pablo, ley natural, iusnaturalismo, teología natural, razón.

\begin{abstract}
In the history of Legal Philosophy, natural law concept, reflected in both two first chapters of the Letter of San Pablo to the Romans, means the birth of a new Iusnaturalism. This concept takes roots in the greco-roman classic thought and is based on the new anthropological dimension that provides Christianity. From the Apostle critical view regarding the mosaic law, we can analyse the idea of a nonwritten law that flows from human nature. This law is born in men's heart and works for grace and true justice, represented by Gospel. In addition this natural law constitutes an unequivocal test of the existence of a natural ethics and a theology based on reason.
\end{abstract}

Key words: San Pablo, natural law, iusnaturalismo, natural theology, reason.

\section{A. INTRODUCCIÓN}

El Apóstol Pablo, de cuyas Epístolas ha bebido durante siglos la teología cristiana, ha sido considerado con fundamento el primer pensador iusnaturalista de la Cristiandad al afirmar la vigencia de una ley natural ínsita en el corazón del hombre y de carácter universal: ante Dios no hay acepción de personas, ni judíos ni gentiles, ni esclavos ni libres, ni bárbaros ni escitas, ni varones ni mujeres, ni circuncisos ni incircuncisos. ${ }^{1}$

1 En relación con el tema del Derecho Natural en San Pablo vid. QUIRMBACH, J., Die Lehre des hl. Paulus von der natürlichen Gotteserkenntnis und des natürlichen Sittengesetzes. Eine biblischdogmatische Studie. (Strassbug. Theol. Stud, 7, 4), Friburgo de Brisgovia, 1906; KUSS, O., San Pablo.La aportación del apóstol a la teología de la Iglesia primitiva. Herder, Barcelona, 1975; sobre las relaciones entre justicia y fe vid. TRESMONTANT,C., Saint Paul et le mystére du Christ, editions du Seuil, 1956,pp.113-120. 
San Pablo representa por ello el nacimiento de un nuevo iusnaturalismo, que, nutriéndose de la filosofía clásica —al igual que el Cristianismo se nutrirá del Judaísmo-, alcanzará su plenitud siglos más tarde con el desarrollo de la Escolástica. Porque hasta ese momento en que irrumpe el Cristianismo en el mundo romano de la mano de San Pablo, el derecho natural grecorromano había mantenido un carácter marcadamente intelectualista, ignorando la función específica de la voluntad en el acto de la decisión, disolviendo la voluntad en la razón o en el instinto. Pohlenz y Suell han llamado la atención sobre el hecho de que el idioma griego no posea ninguna palabra para designar el querer como acto puro, y por tanto ninguna palabra para referirse a la voluntad como función específica del espíritu. ${ }^{2}$ Todo ello se refleja obviamente en las dos grandes concepciones griegas sobre el derecho natural; la primera, una concepción como función de verdades racionales eternas, predeterminadas por el lógos desde toda una eternidad, y que configura el derecho natural idealista de Platón y Aristóteles; la segunda es una concepción de las leyes naturales como imposición física de carácter vital e instintivo, esto es, el derecho natural existencialista de algunos sofistas como Calicles y Carnéades.

Con San Pablo y el Cristianismo se altera este panorama, abriéndose paso una nueva concepción del derecho natural, al amparo de una nueva dimensión antropológica, de una nueva valoración del hombre y de cuanto configura lo humano. ${ }^{3}$

Porque el Cristianismo es mucho más que una nueva religión, un sistema filosófico o una nueva weltanschaung: el Dios del Cristianismo sale al encuentro del hombre y le revela verdades decisivas. Scheler afirma que el Cristianismo otorga al hombre una importancia cósmica y metacósmica que resulta incomparable con la concepción clásica grecorromana de la persona. En el pensamiento cristiano la personalidad individual queda profundamente subrayada y se recalca la idea de dignidad de la persona, concebida como fin en si misma: en ello se fundamentará la condena de la esclavitud, la ilicitud del suicidio, la dignificación del trabajo, la santificación del matrimonio, la función social de la propiedad... Y prevalecerá, sobre todo, el primado del amor al prójimo, ese mensaje cargado de amor que llama al amor en palabras de Bergson.

De otra parte, en Pablo va a afirmarse una mentalidad voluntarista, que va a contrastar con el derecho natural idealista representativo del espíritu griego. La voluntad de Dios se afirma como fuente de lo justo, ya que Dios, que ha creado el mundo de la nada, ha establecido las normas que separan lo justo de lo injusto. Ante el Creador son otras fuerzas distintas a las de la inteligencia y el conocimiento las que se hacen valer: «Pero, ¿quién eres tú, pobre hombre, para exigir cuentas a Dios? ¿Es que un vaso de barro puede decir al que lo ha modelado: por qué me has hecho así? ¿O es que el alfarero no puede hacer del mismo barro tanto un vaso de lujo.como uno corriente? Así es Dios. Cuando quiere manifiesta su ira y da a conocer su poder; pero puede soportar con gran paciencia a los que se han hecho objeto de ira y se han puesto en camino de perdición.» (Rom 9, 20-22).

\section{B. LA LEY MOSAICA EN LA CONCEPCIÓN DE SAN PABLO}

El estudio del concepto de ley natural debe partir forzosamente del concepto de ley mosaica, la ley veterotestamentaria, verdadero punto de arranque. Porque para Pablo los cristianos están muertos a la ley y la ley está muerta para ellos (Cf. Rom 7, 4-6; Gal, 2, 19; Col $2,20)$.

La ley de la Biblia ha sido, ante todo, expresión de un orden de cosas religioso, instaurado por la alianza del Sinaí entre Dios y los hombres, concluida con Israel como realización de

2 Citado por WELZEL, H.,Derecho Natural y Justicia Material, Madrid, 1957, p.56

3 Cf. MENEGHELLI, R., Cristianesimo e storia, Cedam, Padova, 1966. 
un designio divino que se remonta a la creación del primer hombre y que será hecho efectivamente universal por Cristo. Pero la ley bíblica terminó siendo un pacto contractual que trazaba vínculos jurídicos racionales entre el pueblo elegido y la divinidad, estableciendo pautas legales de convivencia para el logro de la salvación de Israel. Según recoge Aubert, esta tendencia a rebajar la ley santa a un nivel utilitario y jurídico se debió mas a una especie de letargo espiritual (a una propensión a no ver más que el aspecto exterior de la alianza) que a la verdadera finalidad de la ley. De ahí que los progresos y resurgimientos de Israel tuvieron siempre por resultado redescubrir la pureza interior y religiosa de la ley; tanto en los profetas (Cf. Ez 22, 26; Jer 11, 1-12), como en los sabios (Cf. Eccli 24, 23) o en el libro de los Salmos (Cf. Sal $19,8 ; 119)$, la ley aparece siempre como el fundamento de las relaciones personales con Dios. ${ }^{4}$

Pero, ¿puede hablarse en Pablo de ruptura total con la ley de Israel? ¿O simplemente se trata de remarcar enfáticamente el nuevo sentido que la ley debe alcanzar para el cristiano? Se ha señalado que el Apóstol de las gentes, con su genio teológico, captó muy bien el universalismo del mensaje de Cristo en su proyección netamente espiritual para la liberación del complejo de pecado del hombre, con sus ansias de rehabilitación profunda. De ahí que, al predicar el Evangelio en las sinagogas, chocara muy pronto con el rigor judío de la interpretación literalista de la Torah. Por eso, en sus primeras epístolas intensifica el tono polémico contra le ley, exagerando sus deficiencias con frases radicales que, si se tomaran aisladamente, darían a entender que la ley de Moisés fue sólo un obstáculo y no una preparación para la proclamación del mensaje evangélico ${ }^{5}$. Si la ley veterotestamentaria estaba ligada a la carne, a la condición y a los fines mundanos del hombre, con Cristo la carne se redime y triunfa el espíritu: «Sin embargo, la misma ley me ha llevado a romper con la ley, a fin de vivir para Dios. Estoy crucificado con Cristo, y ya no vivo yo, sino que es Cristo quien vive en mí» (Gal 2, 19-20).

En esta idea insiste Larcher ${ }^{6}$ : el apóstol Pablo en lugar de mostrar la ley cumplida por Cristo, destaca sus insuficiencias, denuncia sus complicidades con el pecado, la considera una intrusa en los planes de Dios, porque ha hecho desviar la promesa de salvación. Por eso la ley mosaica sería desde entonces incompatible con la libertad del Espíritu, con el Espíritu que da la vida en Cristo Jesús (Rom 8,2). Además, Cristo ha venido a cumplir la promesa, no la ley (Cf. Gal, 3,10). Una contraposición promesa- ley bien trazada en la carta a los Gálatas, que simboliza el valor primordial de la promesa de salvación, en cuanto guía y camino a la vida eterna, y el valor subordinado y transitorio de la ley (frente al judaísmo tardío que había divinizado la ley recibida por Moisés en el Sinaí).

Por ello no puede extrañar que algunos autores hayan tomado al pie de la letra el texto, como es el caso de Lutero, que llega a considerar la ley como una institución mala en sí misma, una obra del espíritu del mal o un castigo de Dios. Sin embargo, para conocer el pensamiento de Pablo es preciso tener en cuenta otras declaraciones que matizan más su concepción de la ley, que es una obra de Dios, y sólo fracasó parcialmente por el mal uso que de ella hicieron los hombres.?

Analizando el capítulo 7 de la Carta a los Romanos ${ }^{8}$, observamos que todo el razonamiento desarrollado en el mismo incide en el tema de la muerte como término de las obliga-

4 AUBERT, J.M., Ley de Dios, leyes de los hombres. Herder, Barcelona, 1969, p.30

5 GARCIA CORDERO, M., Teología de la Biblia, tomo III, BAC, Madrid, 1972, pp. 346-347.

6 LARCHER,C., L'actualité chrétienne de l'Ancien Testament, Paris, 1962. p.254

7 GARCIA CORDERO, M., Op.cit. p.347.

8 Sobre la Carta a los Romanos y su significación teológica cf. BORNKAMM,G., El nuevo testamento y la historia del Cristianismo primitivo. Ed.Sígueme, Salamanca, 1975, pp.116-122. Asimismo cf. CERFAUX, L., Itinerario espiritual de San Pablo, Herder, Barcelona, 1968, pp. 141-172. PRÜMM, K., Il messagio della lettera ai Romani, trad.it., Brescia, 1964. SCHULZE, W.A., «Römer 13 und das Winderstandsrecht», Archivs für Recht und Sozial Philosophie, XLII (1956),pp.555-566. GONZALEZ RUIZ, JOSE Mª , El Evangelio de Pablo. Ediciones Marova, S.L., 1977, pp. 120-158. 
ciones terrenas. Así, por ejemplo, es la muerte la única realidad que rompe el vínculo matrimonial: «En efecto, la mujer casada está atada por la ley al marido mientras éste vive; mas una vez muerto el marido, queda desligada de la ley del marido. Así que mientras vive el marido será declarada adúltera si se junta a otro hombre; mas, una vez muerto el marido, queda libre de la ley, de suerte que no es adúltera si se junta a otro hombre.» (versículos 2-3).

Análogamente, razona Pablo, con la incorporación a Cristo se produce la muerte jurídica y mística del cristiano a la antigua ley, el hombre redimido se libra de toda sujeción respecto a la antigua ley: «Así es que, hermanos míos, también vosotros quedáis muertos a la ley por el cuerpo de Cristo, a fin de que pertenezcáis a otro, a aquel que fue resucitado de entre los muertos, con el fin de que llevemos fruto para Dios.» (Rom 7,4). Esta ley es sin duda alguna la ley de Moisés, la ley del judaísmo que en ningún caso se puede identificar con el pecado, pero a la que Pablo reconoce un poder de implementación del pecado, por el mal uso que se ha hecho de ella: «Porque cuando estábamos en la carne, las pasiones de los pecados, vigorizadas por la ley, obraban en nuestros miembros para llevar fruto en pro de la muerte; mas ahora nos desentendimos de la ley, habiendo muerto a aquello que nos tenía apresados, de modo que sirvamos en espíritu nuevo y no en letra vieja» (Rom 7; 5-6).

Por consiguiente no es que Pablo afirme que la ley sea pecado, pero sí que es motivo de conocimiento del mismo: «QQué diremos pues? ¿La ley es pecado? Eso no; sin embargo, el pecado no lo conocí sino por la ley». Porque ni la concupiscencia conociera si la ley no dijera: «no codiciarás» (Éxodo,20,17). «Mas tomando ocasión el pecado por medio del mandamiento activó en mí toda concupiscencia, porque sin ley el pecado estuviera muerto. Y yo viví algún tiempo sin ley, pero, sobreviniendo el precepto, revivió el pecado, y yo quedé muerto, y hallé que el precepto, que era para vida, fue para muerte. Pues el pecado, con ocasión del precepto, me sedujo y por él me mató. En suma, que la ley es santa, y el precepto santo, justo y bueno. ¿Luego lo bueno me ha sido muerte? Nada de eso; pero el pecado, para mostrar toda su malicia, por lo bueno me dio la muerte, haciéndose por el precepto sumamente pecaminoso. Porque sabemos que la Ley es espiritual, pero yo soy carnal, vendido por esclavo al pecado. Porque no sé lo que hago, pues no pongo por obra lo que quiero, sino que lo que aborrezco, eso hago. Si, pues, hago lo que no quiero, reconozco que la Ley es buena... Porque me deleito en la Ley de Dios según el hombre interior, pero siento otra ley en mis miembros que repugna a la Ley de mi mente y me encadena a la ley del pecado, que está en mis miembros...Así, pues, yo mismo, que con la mente sirvo a la Ley de Dios, sirvo con la carne a la ley del pecado» (Rom 7, 7-25)

En la concepción paulina el pecado que dormitaba en el corazón del hombre se reaviva, sé intensifica o potencia gracias a la ley, y por ella priva al hombre de la salud del alma. Sin embargo, San Pablo considera que la ley es buena en sí, pero el pecado la instrumentaliza, abusa de ella para producir la muerte. Por ello puede concluirse que, una vez matizados los enfoques particulares - a veces contradictorios-y valorando el estilo radical que el Apóstol utiliza en sus Cartas, tendente a formulaciones extremas, en general la ley del Antiguo Testamento tuvo un valor más negativo que positivo, porque no logró dar vida espiritual sino sólo señalar un camino jurídico, «contabilizando una serie de intimaciones y prohibiciones y dejando al hombre a la intemperie, sin fuerza interior para cumplirlos. ${ }^{9}$

$Y$ es que la ley del Antiguo Testamento, en sí misma considerada, no es más que una luz que esclarece la inteligencia sin afirmar la voluntad, no es mas que una barrera que despierta el espíritu de rebeldía sin refrenarlo. De hecho, en la historia del pueblo de Israel, la ley no fue más que un obstáculo importante a la irrupción del pecado y al desbordamiento del mal. Pero si hubiese sido bien observada, habría sido una causa de justificación, un manantial de méri- 
tos: «Porque no salvará Dios a los que simplemente escuchan la ley, sino a aquellos que la cumplen» (Rom 2, 13).

Con todo San Pablo no dejó de reconocer el valor pedagógico de la ley veterotestamentaria, puesto que tuvo el honor de ser la depositaria del monoteísmo y de la verdad revelada; fue un beneficio concedido por Dios al pueblo de la Alianza, una prerrogativa de Isràel: «Antes de que llegara la fe, éramos prisioneros de la ley y esperábamos encarcelados que se nos revelara la fe. La ley nos sirvió de acompañante para conducirnos a Cristo y alcanzar así la salvación por medio de la fe. Pero al llegar la fe, ya no necesitamos acompañante» (Gal 3, 23-25).

Por consiguiente, desde la llegada de la fe, la ley del Antiguo Testamento debía ser superada, y el apóstol Pablo es particularmente incisivo en ese asunto, como lo demuestran sus epístolas, y muy particularmente la Carta a los Gálatas, dirigida a solventar la crisis provocada en las comunidades cristianas del norte de Galacia - la actual Turquía continental - por las comunidades judaizantes, que proclamaban como auténtico el evangelio de los apóstoles de Jerusalén, y ordenaban observar fielmente la ley de Moisés.

Sin embargo, se ha señalado que, después de hacer tabla rasa de la ley mosaica, Pablo jamás dice claramente con qué la reemplaza. ${ }^{10}$ Sostiene Prat que éste es un punto delicado - por no decir el punto débil- de la moral de Pablo. No cabe mantener la vigencia de la ley antigua bajo ningún concepto, puesto que la distinción realizada por algunas exegetas entre la ley ceremonial y la ley moral, en virtud de la cual la primera sobreviviría y continuaría sirviendo de norma en las comunidades cristianas, mientras que la segunda sería herida de muerte por Cristo, es una sutileza desconocida para el Apóstol; por el contrario mantendría siempre la abolición total de la Thorá, tanto para los judíos como para los gentiles, por cuanto el código sinaítico sería indivisible, un edificio que subsiste o cae todo entero. Estas ideas, plenamente aceptadas y convertidas en decreto en la reunión apostólica del año 50, antes de haber escrito las Cartas, nunca variaron después. ${ }^{11}$

Para el Apóstol de los gentiles la liberación del yugo de la ley mosaica no significa la exención de todo freno, porque la libertad de los cristianos no puede ser nunca libertinaje: «Es cierto, hermanos, que habéis sido llamados a la libertad. Pero no toméis la libertad como pretexto para vuestros apetitos desordenados; antes bien, haceos esclavos los unos de los otros por amor» $(\mathrm{Gal} 5,13)^{12}$. Nunca dijo que Dios hubiera derogado la economía antigua sin sustituirla por otra más perfecta, porque desde el momento en que Jesús abolía el régimen de la ley mosaica, sentaba las bases del nuevo régimen de la gracia.

Ante esta tesitura cabe preguntarse por el concepto de ley natural, sus relaciones con la ley evangélica o de la gracia, y su papel en la reconstrucción de un código nuevo —el evangélico- que sustituiría al desechado código de Moisés.

\section{LA LEY NATURAL: LOS DOS PRIMEROS CAPÍTULOS DE LA CARTA A LOS ROMANOS}

En los Evangelios no se halla la expresión ley natural, nacida en el contexto cultural del pensamiento antiguo grecolatino. Sin embargo, la realidad que designa está frecuentemente supuesta en las enseñanzas evangélicas. Más de una vez Cristo daba a entender que sus oyentes sabían distinguir por sí mismos el bien del mal, es decir, lo que es justo por la naturaleza misma de las cosas (Mc 3, 3; 7, 20-23; Jn 5, 29). Otras veces apela a esta ley de la naturaleza, principalmente a propósito de la indisolubilidad del matrimonio (Mt 5, 27 y ss; 5, 31 y ss; 19, 3-12)

10 . PRAT, F., La Teología de San Pablo, II parte, Edit. Ius, México, 1947. pp.356-357.

11 PRAT, F., Op.cit., p.357.

12 PRAT, F. Op.cit. p.358. 
o para reconocer la legitimidad de instituciones naturales como el poder político (Mt 22, 21; Mc 12,17 ; Lc 20, 25). ${ }^{13}$

San Pablo es más preciso y explícito, cuando trata de una ley no escrita a la que están sometidos los paganos, que no es ni la ley mosaica ni la nueva ley de Cristo - que ignoran-, sino que es la que fluye de la simple naturaleza humana, y cuyas exigencias son inmutables.

Esta concepción de la ley natural se prefigura en la Epístola a los Romanos, que contiene en su seno lo que ha dado en llamarse la Carta Magna del iusnaturalismo cristiano ${ }^{14}$. Está datada en el invierno del año 56 (o 57) de la era cristiana. Hacia el año 42, según la tradición, Pedro, el Príncipe de los Apóstoles, había llegado a Roma desde Jerusalén, donde había intensificado su apostolado, especialmente entre los judíos y prosélitos que habitaban la capital del Imperio. Al parecer, la atención inicial a los judeo-cristianos -el primer núcleo de la Iglesia romana- dio pasó a una apertura a los gentiles, al producirse la expulsión de los judíos de Roma por el emperador Claudio en el año 49. Desde entonces la Iglesia de Roma, en su práctica totalidad, se formó a partir de la gentilidad, lo que la preservó de una fuerte tendencia judaizante que afectó hondamente a las Iglesias de Galacia y de Corinto.

Se ha indicado que la Carta a los Romanos constituye el auténtico Evangelio de San Pablo. Un Evangelio que pretende acercar a todos los hombres - aunque priorizando claramente a los judíos-el mensaje salvífico de Jesucristo: «Así, cuanto de mi depende, hay ánimo pronto para anunciar el Evangelio también a vosotros los que habitáis en Roma. Porque no me averguienzo del Evangelio. Pues es una fuerza de Dios, ordenada a la salud. Para todo el que cree, así para el judío, primeramente como para el gentil». 15 Los escrituristas dividen la carta en dos partes claramente diferenciadas, sin contar con el prólogo y el epílogo. La parte primera está dedicada a la dogmática (capítulo 1, 18-11) y la segunda a la moral (12-15,13). A su vez la parte dogmática de la Epístola se subdivide en tres secciones: la primera versa sobre la Justicia de Dios revelada en el Evangelio por la fe $(1,18-4)$; la segunda relativa al Evangelio como fuerza de Dios en orden a la salud; y la tercera dedicada específicamente a la participación de los judíos en la salud.

Es precisamente en el capítulo segundo de la Carta donde se sitúa el eje central de la teoría paulina sobre el iusnaturalismo, el lugar clásico de la Biblia donde parece enseñarse la existencia de una ley natural ${ }^{16}$; esto es, la que constituye la «Carta magna» del iusnaturalismo cristiano: «En efecto, todo el que haya pecado sin estar bajo la ley, también perecerá sin que intervenga la ley; y todo el que haya pecado estando bajo la ley, será juzgado por esa ley. Porque no salvará Dios a los que simplemente escuchan la ley, sino a aquellos que la cumplen. $Y$ es que cuando los paganos que no están bajo la ley, cumplen lo que atañe a la ley por inclinación natural, aunque no tengan ley, se constituyen en ley para sí mismos. Llevan los preceptos de la ley escritos en sus corazones, como lo atestigua su conciencia y también sus propios razonamientos que los acusarán o defenderán en el día en que Dios juzgue las cosas ocultas de los hombres por medio de Jesucristo y conforme al evangelio que yo anuncio» (Rom 2, 12-16).

Pablo habla de la existencia de una ley natural en el fondo de los corazones humanos, grabada de forma indeleble, de manera que los paganos pueden también encontrar en su interior, sin necesidad de salir de sí mismos, la ley de Dios. Esto es; la distinción entre el bien y el mal es posible tanto para el pagano como para el judío y el cristiano, lo que quiere decir que esa distinción se basa en la propia naturaleza de las cosas tal como es perceptible por la razón.

13 AUBERT, J.M., Ley de Dios, leyes de los hombres. Herder, Barcelona, 1969, p.66.

14 TRUYOL Y SERRA, A., Historia de la Filosofia del Derecho y del Estado. Tomo I. Alianza Universidad Textos, Madrid, 1982. p. 242.

15 Rom 1,15-16.

16 OSUNA FERNÁNDEZ-LARGO, A., Derecho Natural y Moral cristiana: estudio sobre el pensamiento ético-jurídico de Karl Barth y otros autores reformados. Salamanca, Editorial San Esteban, 1978, p.210. 
Ante todo cabe indicar que Pablo está reconociendo claramente la existencia de la ley natural, tanto en ese pasaje como en uno anterior (Rom 1,32$)$ donde declara que los paganos son inexcusables por haberla violado: «Conocen bien el decreto de Dios según el cual los que cometen tales acciones son dignos de muerte, pero no contentos con hacerlas, aplauden incluso a los que las cometen».

El Apóstol parte del principio esencial de que toda justificación proviene de Cristo: «la justicia de Dios... se ha manifestado por la fe en Jesucristo, para todos los que creen, sin distinción alguna» (Rom 3, 21-22). Así, todos los hombres tienen necesidad de la justificación en Cristo, porque todos son culpables ante Dios: «todos, tanto judíos como gentiles, son esclavos del pecado, según está escrito: no hay un solo justo siquiera». (Rom 3, 9). Los judíos porque no fueron fieles a la ley de Dios; los paganos por no seguir los preceptos de la ley natural de la conciencia, cayendo en todos los extravíos morales (el pecado contra natura, la injusticia, malicia, codicia, perversidad,...).

Hay que advertir que en ningún caso el Apóstol utiliza el nombre de ley natural, porque él reserva esa expresión para la ley positiva. Así, los paganos son para sí mismos su ley, por analogía, porque hallan en sí mismos una luz que reemplaza a la ley. ${ }^{17}$

Pablo concede así realidad autónoma a una ley que guía a los hombres y es para ellos norma, y a la cual llamamos ley natural. ${ }^{18}$ La gracia de Cristo penetra todo lo humano, pero no aniquila la razón natural, sometida a un juicio superior (el de la salvación redentora de Cristo) y a otra realidad, que es la que verdaderamente hace al hombre justo (la gracia de salvación otorgada por Jesús). ${ }^{19}$ Se ha afirmado, desde la misma teología, que no se puede exponer en términos más explícitos el valor de la conciencia iluminada por la mera razón humana. Por eso los que se oponen a esta ley de la conciencia iluminada por la razón son inexcusables y caen en todos los extravíos morales. ${ }^{20}$

Para Osuna, el capítulo segundo de la Carta a los Romanos es la prueba convincente de la existencia de una ética natural de la razón, válida para todos los hombres y previa a la comprensión de nuestra justificación por la fe en Cristo, siguiendo las tesis apuntadas por B. Schüller, que defendió con éxito que la especificidad de la ética cristiana presupone necesariamente una eticidad humana en el hombre, y sin la cual aquella no tiene sentido. Esto no quiere decir que la revelación cristiana, y el cristianismo en sí como religión, se haya construido sobre el pilar de una ética natural. Pero sí que, una vez aceptada por la fe la revelación, haya encontrado en la ética humana, y sobre todo, en la ideología del derecho natural, un poderoso elemento de contraste y un señuelo en orden al cual debe definirse. ${ }^{21}$

Para Truyol, en el conocido pasaje del capítulo segundo de la Carta a los Romanos, San Pablo establece una graduación a la vez ontológica e histórica entre la moralidad natural y la sobrenatural. La ley natural, al igual que la mosaica, debe culminar en la ley evangélica, y abarca un orden de rectitud mundanal que prepara el de la plenitud sobrenatural. De modo que las virtudes teologales desarrollados por el cristianismo - la fe, esperanza y caridad, dando prioridad a esta última - se sobreponen, sin desplazarlas, a las virtudes cardinales de la filosofía moral griega. ${ }^{22}$

17 PRAT, F., Op.cit., p.358.

18 Es preciso delimitar los distintos sentidos en que su usa el término ley en el cap.VII de la Carta a los Romanos. Prat distingue hasta cinco distintos: ley de la experiencia, ley de Dios o mosaica, ley de los miembros, ley de la razón o ley natural y ley del pecado. Vid. PRAT, Op.cit. p.254. Asimismo QUADRI, G., «Il fondamento del diritto di punire nel pensiero di S.Paolo», en Rivista Internazionale di Filosofia del Diritto, XIV (1934),p.367 y ss.

19 OSUNA FERNANDEZ-LARGO, A., Op.cit., pp.210-211.

20 GARCIA CORDERO, M., Op.cit., p.326.

21 OSUNA FERNANDEZ-LARGO, A, Op.cit., pp. 219-220.

22 TRUYOL Y SERRA, A., Historia de la Filosofia del Derecho y del Estado. Tomo I. Alianza Universidad Textos, Madrid, 1982, p.242. 
Se viene afirmando desde la iusfilosofía que el texto paulino de la Carta a los Romanos es la piedra angular del futuro iusnaturalismo cristiano, ${ }^{23}$ al afirmar que el conocimiento de la ley natural es directo; que la razón humana, con independencia de raza, credo religioso o cualquier otra condición, puede conocerla por sí misma. Se han visto huellas claras de la filosofía estoica en esa concepción paulina, al igual que puede encontrarse en otros textos esenciales del cristianismo, como el prólogo del Evangelio de San Juan cuando habla del lógos, interpretado como verbo o razón divina. ${ }^{24}$

Pero el texto de Romanos interesa, además, sobremanera a la teología, por cuanto se reconoce en dicho pasaje explícitamente la existencia de una teología natural, cuando afirma que también los paganos pueden tener un verdadero conocimiento de Dios gracias a las obras visibles de la creación, dejándose conducir por la simple razón. A este respecto recuerda Aubert que el famoso pasaje de la Carta a los Romanos ha sido objeto de una declaración doctrinal de la Iglesia ${ }^{25}$, y que el Concilio Vaticano I definió directamente la capacidad directa de cualquier hombre para conocer a Dios por medio de su razón natural, incluyendo los principios fundamentales de la ley natural. Así el Concilio afirma que: «la misma santa madre Iglesia sostiene y enseña que Dios puede ser conocido con certeza como principio y fin de todas las cosas, por la luz natural de la razón humana a partir de las cosas creadas.» ${ }^{26} \mathrm{Y}$ paralelamente, las encíclicas Casti connubii de Pio XI y Humani generis de Pio XII han aplicado al conocimiento de la ley moral natural lo que el Concilio había afirmado del conocimiento de Dios. ${ }^{27}$

Truyol cree que, con ese descubrimiento de Dios y de algunos de sus atributos visibles los de la creación - se admite la eficacia de la razón, aunque en un ámbito limitado. Porque nunca podrá elevarse la sabiduría humana al plano de la sabiduría divina, que se comunica por medio de la fe en Cristo Jesús y que pareció a los judíos escándalo y a los griegos necedad (I Cor, 1, 22-25). ${ }^{28}$

\section{LA LEY NATURAL AL SERVICIO DE LA LEY DEL EVANGELIO}

El contenido de lo que venimos llamando ley natural, y que en Pablo no recibe propiamente ese título, sino que es simplemente luz interior de la razón que hace las veces de ley, se diluye en sucesivos pasajes de las epístolas paulinas. Pero en su consideración no puede obviarse nunca esa íntima vinculación con la idea natural de Dios, con lo que hemos denominado teología natural: «En efecto, la ira de Dios se manifiesta desde el cielo contra la impiedad e injusticia de aquellos hombres que obstaculizan injustamente la verdad. Pues lo que se puede conocer de Dios, lo tienen claro ante sus ojos, por cuanto Dios se lo ha revelado. Y es que lo invisible de Dios, su eterno poder y su divinidad, se ha hecho visible desde la creación del mundo, a través de las cosas creadas. Así que no tienen excusa, porque, habiendo conocido a

23 No puede obviarse que existen tesis que cuestionan ese iusnaturalismo paulino. Es el caso de GUIDO FASSÒ, que estima que, aunque San Pablo hubiera reconocido la existencia de una ley natural de alcance universal, no por ello podría ser considerado iusnaturalista. Para Fassó, el antilegalismo es tan fuerte en el Apóstol que no puede admitirse que esté atribuyendo valor a esa ley escrita en los corazones, asimilable a la ley mosaica, y por tanto rechazada por ser propia de una humanidad aún no redimida y esclava del pecado. Así sólo la fe en Jesucristo salva y hace justo al hombre, sólo la enseñanza evangélica del amor a Dios y la Caridad hacia el prójimo, basada en al amor a Dios. Vid. FASSÓ G., Storia della Filosofia del Diritto, Volume I. Il Mulino, Bologna 1966, p. $172-176$.

24 TRUYOL Y SERRA, A., Op.cit., p.242.

25 Se trata de la proposición 22 de Bayo, condenada por Pio V. Cf. DENZINGER-SCHÖNMETZER, Enchiridion symbolorum, definitionum et declarationum de rebus fidei et morum. r.1022. Herder, Barcelona 1963.

26 DENZINGER, Op.cit., 3004.

27 AUBERT, J.M., Op.cit., p.122.

28 TRUYOL Y SERRA, A., Op.cit. p. 242 
Dios no lo han glorificado, ni le han dado gracias sino que han puesto sus pensamientos en cosas sin valor y se ha oscurecido su insensato corazón» (Rom 1, 18-23).

En la concepción paulina la ley natural se corresponde con el orden natural de la creación, de ahí que los paganos puedan tener un verdadero conocimiento de Dios por medio de las obras visibles de la creación, y con la ayuda de la razón humana. Así, la distinción entre el bien y el mal es posible lo mismo para un pagano que para un judío o un cristiano, precisamente porque el criterio valorativo de lo bueno y de lo malo se basa en la propia naturaleza de las cosas, y es perceptible por la razón humana dejada a sus propias fuerzas. Esa ley no escrita a la que están sometidos incluso los paganos es la que afluye de la simple naturaleza humana, y cuyas exigencias son inmutables. ${ }^{29}$

Por consiguiente, si el contenido de la ley natural viene determinado por la propia naturaleza de las cosas, la razón lo mostrará como evidente. Por eso ir contra la ley natural es una aberración humana, como sucede con el pecado contra naturam (Rom 1, 26-27); por el contrario, el amor conyugal es bueno y deseable (Tit 2, 4-5; Ef 5, 25-33); e igualmente es conforme al bien la vida familiar basada en el amor entre los miembros de ella, a la que debe asemejarse la vida en comunidad. Las referencias a las relaciones familiares son abundantes: el apóstol utiliza la expresión «hijos míos» y alude a una verdadera «paternidad» espiritual para amonestar a los cristianos de Corinto (Cf. 1 Cor 4,14-15); y se refiere a las actitudes del buen padre de familia como imprescindibles para quien debe asumir la responsabilidad de la comunidad (Cf. 1 Tim, 3, 4).

Por otra parte el hombre es naturalmente sociable, y de esa sociabilidad natural se desprende que los miembros de la sociedad serán solidarios entre sí con derechos y deberes mu$\operatorname{tuos}^{30}$ (1 Cor 12, 12-26). Por imperativo de la ley natural San Pablo afirmará que «el que no quiera trabajar que no coma» ( 2 Tes $3,10-13$ ) y que «el labrador que se fatiga es el primero que debe participar del fruto de su trabajo» (2 Tim 2,6). Si Epícteto proclamaba que era preciso seguir lo bueno y huir de lo malo, San Pablo haciéndose eco del mismo principio natural declara: «tribulación y angustia para todos cuantos hagan el mal: para los judíos, por supuesto, pero también para los que no lo son; gloria, honor y paz para los que hacen el bien: para los judíos, desde luego, pero también para quienes no lo son, pues en Dios no hay lugar a favoritismos» (Rom 2, 9-10). ${ }^{31}$

En los mismos relatos evangélicos, y en las epístolas paulinas se recogen los preceptos más elementales de la ley natural, que son la base de toda convivencia social y familiar. Pero el cumplimiento de los mismos no sólo se impone por motivos naturales, sino por exigencias de la nueva ley evangélica. Las exigencias inmutables de la ley natural están llamadas a transfigurarse al servicio de una causa más alta, la del amor cristiano, la de la caridad fraterna, contenido esencial de la ley evangélica que debe inspirar la libertad de los hijos de Dios: «Es cierto, hermanos, que habéis sido llamados a la libertad. Pero no toméis la libertad como pretexto para vuestros apetitos desordenados; antes bien, haceos esclavos los unos de los otros por amor. Pues toda la ley se cumple, si se cumple este precepto: Amarás a tu prójimo como a ti mismo» (Gal 5, 13-14).

En virtud del supremo mandamiento del amor fraterno, los viejos preceptos del Decálogo que recogen la ley natural (no matar, no robar, no cometer adulterio) no solo mantienen su vigencia en la ley nueva, sino que han de guardarse con más diligencia y con un espíritu nuevo: «Con nadie tengáis deudas, a no ser la del amor mutuo, pues el que ama al prójimo ha cum-

29 AUBERT, J.M., Op.cit., p.67.

30 Sobre la obediencia a la autoridad civil y el Estado cf. Los comentarios de Orígenes a la Carta a los Romanos 9, 26-30, en RAHNER, H., Chiesa e struttura politica nel cristianesimo primitivo, Jaca Book, Milano 1990, pp. 54-56.

31 GARCIA CORDERO, Op.cit., pp. 326-327. 
plido la ley. En efecto, los preceptos no cometerás adulterio, no matarás, no robarás, no codiciarás, y cualquier otro que pueda existir, se resumen en éste: Amarás a tu prójimo como a ti mismo. El que ama no hace mal al prójimo; en resumen, el amor es la plenitud de la ley» (Rom 13, 8-10; 2 Cor 7, 2; Ef 4, 28).

La ley veterotestamentaria no ha tenido otra función que la de revelar el pecado y darle nombre, a fin de que el hombre pudiera reconocerlo y rechazarlo, haciéndole tomar conciencia del pecado antiguo presente en la humanidad desde los primeros padres. Pero la vieja ley no podía operar en los hombres esta transformación, esta renovación del corazón por medio del Espíritu Santo, que es la santidad: «Nadie alcanzará la salvación divina por el cumplimiento de la ley; el papel de la ley era hacernos conscientes del pecado» (Rom, 3, 20). Esa transformación integral del hombre por la cual él puede ser llamado justo es la obra de Dios, del Espíritu de Dios. El hombre no puede bastarse a sí mismo para alcanzar la santidad, puesto que esta es una relación de amistad con el Señor, una relación existencial donde el Señor dona esa renovación del corazón que es la Justicia: es de Dios de donde viene el don. ${ }^{32}$

Pero el hecho de que la ley sea impotente por sí sola para justificarnos ante Dios, no implica ni conlleva que podamos contravenir las exigencias espirituales y perennes de la ley. La parte de la ley que San Pablo y el cristianismo consideran como caduca es la parte ritual, las observancias que han perdido su sentido histórico y profético. Pero la sustancia de la ley permanece, porque es la exigencia de santidad. ${ }^{33}$

Recuerda Osuna que la revelación cristiana presupone el contexto de una moral y un derecho que se pueden considerar relativamente autónomos a la justificación divina, en cuanto son ética y derecho normativos y vinculantes de la persona, aunque no lo sean en absoluto, pues la normatividad de la razón y la conciencia están en función de la Creación y de la redención de Cristo. ${ }^{34}$

Se concluye así que la ley natural está siempre al servicio de la gracia, de la verdadera justicia, que no es la que deriva de la naturaleza, ni de la ley positiva, sino del Evangelio. Todo el mensaje evangélico se basa en una visión sobrenatural del mundo y de la existencia del hombre, por lo que, en las argumentaciones de Cristo y de los apóstoles, las apreciaciones sobre la ley natural están en la penumbra y apenas salen a la superficie. Sin embargo el mensaje de Cristo no se basa en un dualismo radical, en el que los valores naturales se opongan a los sobrenaturales, sino que lo natural es elevado y sublimado en aras de una perspectiva superior, al igual que la teología del nuevo testamento se basa en la tradición bíblica veterotestamentaria. ${ }^{35}$

Esa nueva lectura del concepto de ley desde el Evangelio no es ninguna excepción en relación con otros conceptos e ideas que formarán parte del Cristianismo. Señala Grundmann que «là peculiaridad de la fe cristiana no radica en conceptos e ideas originales que no se demuestran fuera de ella misma por los estudios de la historia de las religiones; ni tampoco consiste esa peculiaridad en un nuevo sistema teológico. En ese sentido se encuentran también principios y posibilidades fuera de la fe cristiana. Lo que distingue la fe cristiana del complejo y variado mundo de la antiguiedad y lo que le otorga una fuerza que trasciende todo ese mundo es Jesucristo. Por eso Pablo relaciona estrechamente con Jesucristo y su soberanía todo ese ideario religioso, de origen judío y helenístico, que él utiliza, y que recibe de Jesucristo su contenido cristiano. Ideas y conceptos, que ya existían fuera, son de algún modo bautizados en Cristo». ${ }^{36}$

32 Cf. CULLMANN, O., «Pablo y la Historia de la Salvación» en La historia de la salvación,col.península, edicions 62 s.a., Barcelona, 1967, pp. 277-297.

33 TRESMONTANT, C., Saint Paul et le mystère du Christ, Editions du Seuil, 1956.pp.115-117.

34 OSUNA, Op.cit., p. 236.

35 GARCIA CORDERO, Op.cit., p. 324.

36 GRUNDMANN, W., Der Lehrer der Gerechtigkeit von Qumran und die Frage nach der Glaubensgerechtigkeit in der Theologie des Apostels Paulus en Revue de Qumram n² (1959-1960) pp. 237-259. 
Subyace en todo ello una concepción voluntarista, que contrasta con el idealismo griego, y que lógicamente se terminará extendiendo a la idea de ley natural que hemos analizado (aunque tardará en concretarse varios siglos, hasta la obra de Duns Escoto). Welzel ha llamado a San Pablo el apóstol de la libertad absoluta e inmotivada de Dios. La voluntad divina no tiene otro fundamento para querer como quiere, sino justamente el que $\mathrm{El}$ así lo quiere, porque lo que Dios da, lo da en plena libertad y sólo como gracia. ${ }^{37}$ Aunque el obrar real de Dios no es la arbitrariedad caprichosa de un tirano, sino misericordia de la criatura y justificación del que cree.

Carlos López Bravo

Facultad de Derecho

Universidad de Sevilla

Avda. Cid, s/n

41004 Sevilla

lopezbravo@us.es 